www.jmscr.igmpublication.org

Index Copernicus Value: 79.54

ISSN (e)-2347-176x ISSN (p) 2455-0450

crossrefDOI: https://dx.doi.org/10.18535/jmscr/v7i2.36

Journal Of Medical Science And Clinical Research

\title{
A study on Maternal and fetal outcomes of preterm premature rupture of membrane in Tertiary Medical College Bangladesh
}

\author{
Authors \\ Dr Fahmida Sultana ${ }^{1}$, Dr Anuradha Karmokar ${ }^{2}$ \\ ${ }^{1,2}$ Assistant Professor, Obs \& Gynae, Enam Medical College and Hospital
}

\begin{abstract}
Introduction: To be a mother, a woman must have a happy outcome of her pregnancy, both for the fetus and herself. Many factors influence the outcome of a pregnancy, and premature rupture of membrane (PROM) is one of them.

Objective: In this study our main goal is to estimate the maternal and fetal outcomes of premature rupture of membrane in Bangladesh.

Method: This cross-sectional descriptive type study was carried out from April 2016 to April 2018 at Tertiary Medical College Hospital, Bangladesh where after admission, full history including duration of pregnancy, time and onset of rupture of membranes, past history of rupture of membranes, past obstetric history was taken and data were entered into computer and statistical analyses was done.

Results: In the study majority of the women came from lower middle and poor class of the society where PPROM was more common among multiparous women. 28-30\% neonates suffered from neonatal asphyxia. Chorioamnionitis was common in maternal outcome which was 20.5\% in 32-34 gestational age.
\end{abstract}

Conclusion: PPROM was malnutrition and poverty related disease and for management. extra awareness is needed.

Keyword: Premature rupture of membrane (PROM), Neonatal asphyxia, Chorioamnionitis.

\section{Introduction}

Premature rupture of membranes also known as pre-labor rupture of membranes (PROM), there is a rupture of amniotic sac before the onset of labor. There is a a painless gush or a steady leakage of fluid from the vagina. Complications in the baby may include premature birth, cord compression, and infection. Complications in the mother may include placental abruption and postpartum endometritis. Every woman dreams to be a mother in her life time. PROM is designed when membrane ruptures before the onset of labor.
When membrane ruptures before the onset of labor at a gestational age <37 completed weeks, it is called preterm premature rupture of membrane. PROM at term pregnancy is common, occurring in 6 to 10 percent of all term births. Preterm PROM occurs in approximately $1 \%$ of all pregnancies. It is associated with $30-40 \%$ of preterm birth and is one of the most common underlying causes of preterm delivery and perinatal death.4 In Bangladesh, every year, around 28,000 women die due to complications of pregnancy and childbirth. $^{[1][2][3]}$ 

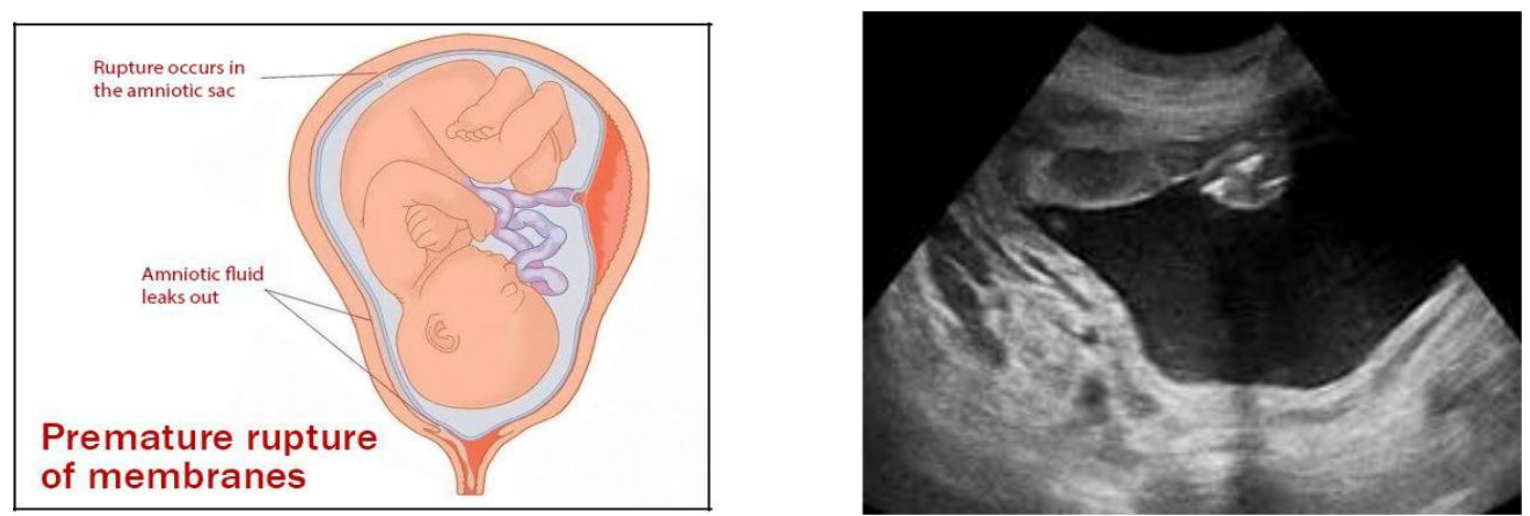

Figure 1a and1b: PROM occur in pregnant women and PROM in ultrasonography ${ }^{[4]}$

Nonscientific intervention in PROM made at various levels intensifies the pregnancy complications several times, thereby leading many more deaths of fetus and newborn. The etiology of PROM is largely unknown. It may be associated with an incompetent cervix, unstable lie, polyhydramnios, multiple gestation or possibly bacteriuria, specially beta-streptococci infection. Infection in the female reproductive tract (Ureaplasma urealyticum, Mycoplasma) is associated with PROM and preterm labor. Proper diagnostic facilities, proper monitoring facilities and a standard protocol in the management can improve the maternal and fetal outcome. ${ }^{[2]}$ In this study our main goal is to evaluate maternal and fetal outcomes of premature rupture of membrane in tertiary medical college of Bangladesh.

\section{Objective}

\section{General objective}

$\checkmark$ To assess maternal and fetal outcomes of preterm premature rupture of membrane.

\section{Specific objective}

$\checkmark$ To detect cause of PROM.

$\checkmark$ To detect maternal outcome.

\section{Methodology}

Study Type: This study was a cross-sectional descriptive type study.

Study place and period: This study was conducted at Department of Obstetrics and Gynecology in Tertiary Medical College Hospital, Bangladesh, from April 2016 to April 2018.

\section{Inclusion criteria}

- Age between 16-35

- Pregnancy duration 28 to 36 weeks 6 days.

\section{Exclusion criteria}

$\checkmark$ Pregnancy 37completed weeks with established labor

$\checkmark$ Pregnancy 37completed weeks with with ante partum hemorrhage and infection

\section{Method}

382 pregnant women with preterm pre-labor rupture of the membrane were recruited from the inpatient of the labor ward of DMCH. Both primi and multi gravid women, who agreed to participate in this study, labor were included in this study. After admission, full history including duration of pregnancy, time and onset of rupture of membranes, past history of rupture of membranes, past obstetric history was taken. Rupture of the membrane was diagnosed by history of a gush of fluid from the vagina or continued leakage of fluid from the vagina and demonstration of membranes rupture has to be made by a sterile speculum examination visualizing flow of amniotic fluid from the cervical os and / or it's pooling in posterior vaginal fornix spontaneously or by fundal pressure and demonstrating alkaline $\mathrm{PH}$ of vaginal fluid by litmus paper.

\section{Data Analysis}

During the study all the data were checked and edited after collection. Then the data were entered into computer and statistical analyses of the results 
were obtained by using window-based computer software devised with Statistical Packages for Social Sciences (SPSS-13) (SPSS Inc, Chicago, IL, USA). The results were presented in tables and figures, the statistical terms included in this study were mean, median, standard deviation, below:

\section{Result}

In figure- 2 shows age distribution of the patients where mean age of the patient was $27.84 \pm 6.278$ years and (31-35) years age group $40 \%$ higher than (21-25) age group. The following figure is given percentage.

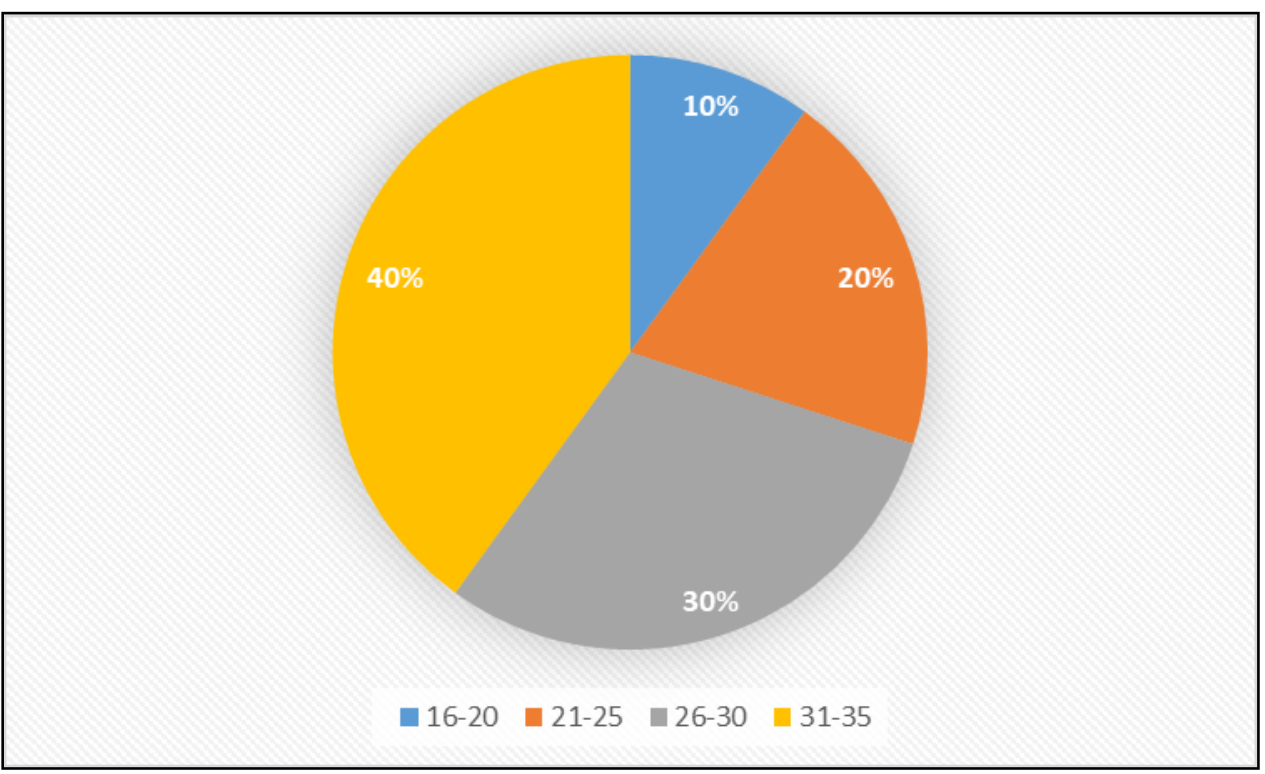

Figure-2: Age distribution of the patients

In table-1 shows demographic characteristics of the patients where 37\%women were multigravida where as $16 \%$ were primi gravida and $36.3 \%$ respondents were educated up to SSC level and remaining $31.9 \%$ women educated up to degree level. The following table is given below in detail:

Table-1: Demographic characteristics of the patients

\begin{tabular}{|c|c|c|}
\hline Variab & & Mean/percentage \\
\hline \multicolumn{3}{|l|}{ Parity } \\
\hline$\square$ & Primi & $16 \%$ \\
\hline & Multigravid & $37 \%$ \\
\hline \multicolumn{3}{|c|}{ Education } \\
\hline & Below primary & $22 \%$ \\
\hline$\square$ & Up to SSC & $48 \%$ \\
\hline & Above SSC & $31.9 \%$ \\
\hline \multicolumn{3}{|c|}{ Antenatal care } \\
\hline & Regular & $23 \%$ \\
\hline & Irregular & $56 \%$ \\
\hline & No & $51.28 \%$ \\
\hline \multicolumn{3}{|c|}{ Occupation } \\
\hline
\end{tabular}




\begin{tabular}{|c|c|}
\hline$\square \quad$ service & $30.1 \%$ \\
\hline Income & \\
\hline $\bar{\square}<4000 /$ taka(monthly) & $45 \%$ \\
\hline$\square \quad 4000-8000 / \mathrm{Tk}$ & $55 \%$ \\
\hline Gestational age in weeks & $34.74 \pm 2.26$ weeks \\
\hline Menstrual period & $5.40 \pm 1.20$ day \\
\hline Menstrual cycle & $27.28 \pm 1.44$ days \\
\hline Birth weight & $2.58 \pm .33 \mathrm{~kg}$ \\
\hline systolic blood pressure (SBP) & $128.9 \pm 9.26 \mathrm{mmHg}$ \\
\hline diastolic blood pressure (DBP) & $71.2 \pm 8.24 \mathrm{mmHg}$ \\
\hline
\end{tabular}

In table-2 shows risk factor that increase the smoking(24\%), over weight $(6 \%)$. The following chance of it occurring where most of the patients table is given below in detail: had urinary tract infection (48\%), followed by

Table-2: Risk factors of the patients

\begin{tabular}{|l|c|c|}
\hline SL No. & Risk factor & Percent \\
\hline 1. & Urinary tract infection & $48 \%$ \\
\hline 2. & Preeclampsia & $14 \%$ \\
\hline 3. & Polyhydramnios & $10 \%$ \\
\hline 4. & Multiple pg & $9 \%$ \\
\hline 5. & Lower genital tract infection & $8 \%$ \\
\hline 6. & Over weight & $6 \%$ \\
\hline 7. & Low socioeconomic status & $4 \%$ \\
\hline 8. & Cervical incompetence & $1 \%$ \\
\hline & Total & $100 \%$ \\
\hline
\end{tabular}

In figure-3 shows mode of delivery of the patients where most of the patients had vaginal delivery $68 \%$ The following figure is given below in detail:

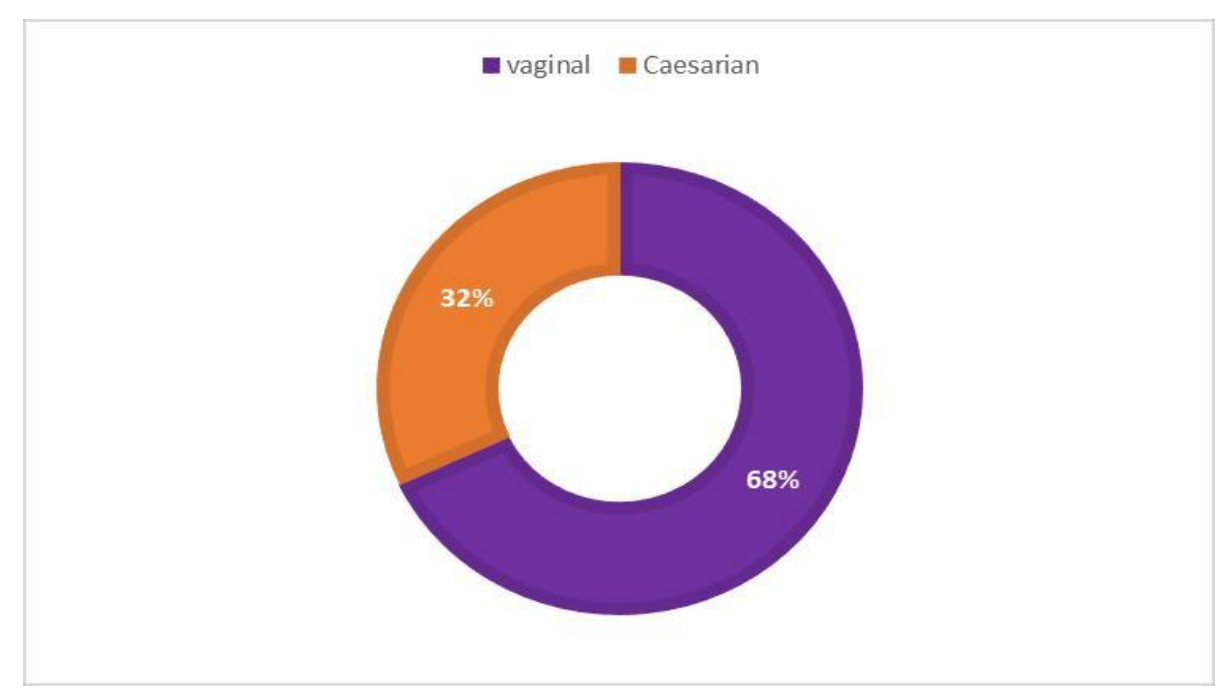

Figure-3: Mode of delivery of the patients 


\section{JMSCR Vol||07||Issue||02||Page 184-192||February}

In table-3 shows distribution of associated tract infection among other diseases. The following diseases. Most of the patients $(32 \%)$ had urinary table is given below in detail:

Table-3: Distribution of associated diseases

\begin{tabular}{|c|c|}
\hline Variable & percent \\
\hline Urinary tract infection & $32 \%$ \\
\hline Hypertension & $25 \%$ \\
\hline Anemia & $15 \%$ \\
\hline Lower genital tract infection & $12 \%$ \\
\hline Diabetes mellitus & $5 \%$ \\
\hline Renal disease & $5 \%$ \\
\hline Heart disease & $6 \%$ \\
\hline Total & $\mathbf{1 0 0 \%}$ \\
\hline
\end{tabular}

In figure-4 shows cervical effacement condition of had cervical effacement 0 to50\% and $31.9 \%$ had the patients during admission where $68.1 \%$ women 51 to $100 \%$. The following figure is given below:

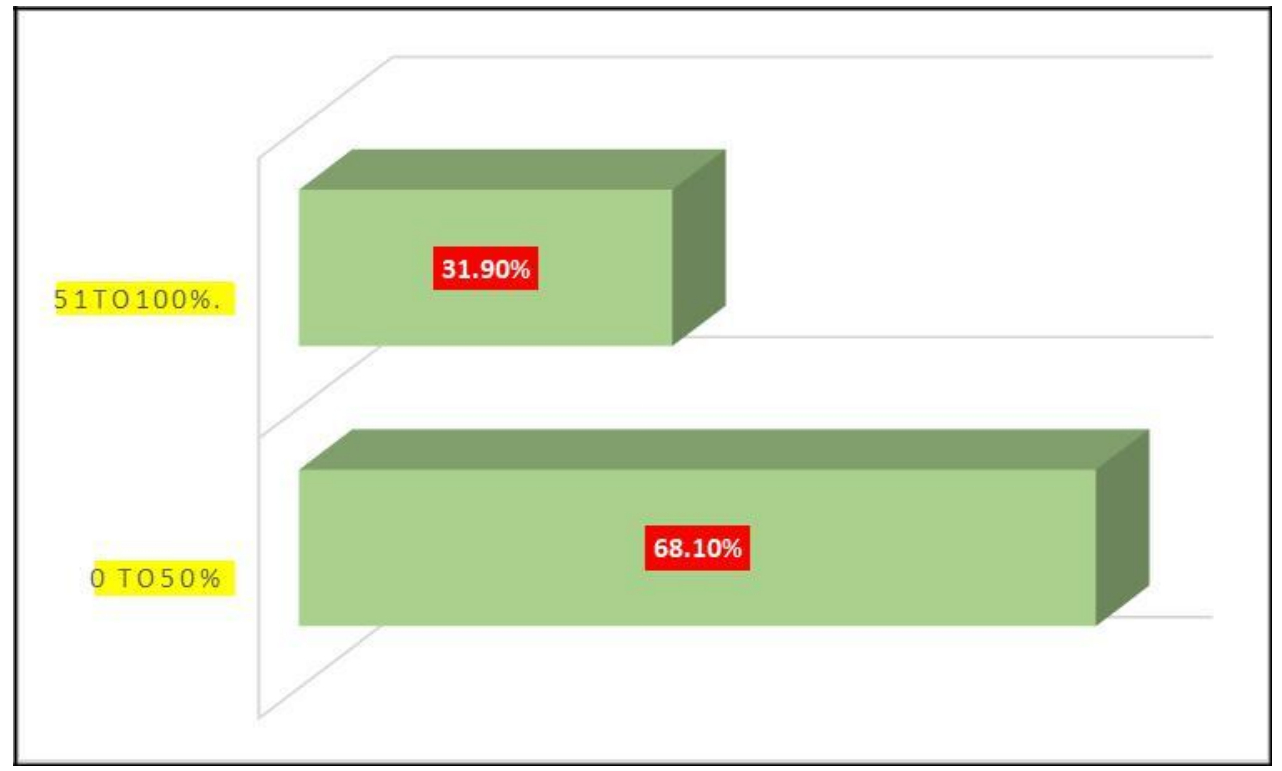

Figure-4: Cervical effacement condition of the patients during admission

In tabel-4 shows distribution of respondents with gestational age and time interval of membrane rupture to the onset of labor pain where mean time interval of onset of rupture membrane and delivery was 27.60 hours with a standard deviation of \pm 21.128 hours. The following table is given below in detail: 
Table-4: Distribution of respondents with gestational age and time interval of membrane rupture to the onset of labor pain $(n=50)$

\begin{tabular}{|l|c|c|}
\hline $\begin{array}{l}\text { Time interval of membrane ruprure } \\
\text { and delivery }\end{array}$ & $\frac{\text { Parity }}{\text { Primi }}$ & $\frac{\text { Parity }}{\text { Multi }}$ \\
\hline$<12$ hour & 2 & 20 \\
\hline $12-24$ hours & 7 & 15 \\
\hline $24-48$ hours & 6 & 7 \\
\hline$>48$ hours & 5 & 4 \\
\hline Undelivered & 5 & 4 \\
\hline $\begin{array}{l}\text { Time interval of membrane ruprure \& } \\
\text { delivery(mean) }\end{array}$ & $27.60 \pm 21.128$ hours & \\
\hline
\end{tabular}

In figure-5 shows fetal outcome in 32-34 neonatal jaundice. The following figure bis given gestational age where $43 \%$ neonates suffer from below in detail: neonatal asphyxia, followed by $22.5 \%$ suffers

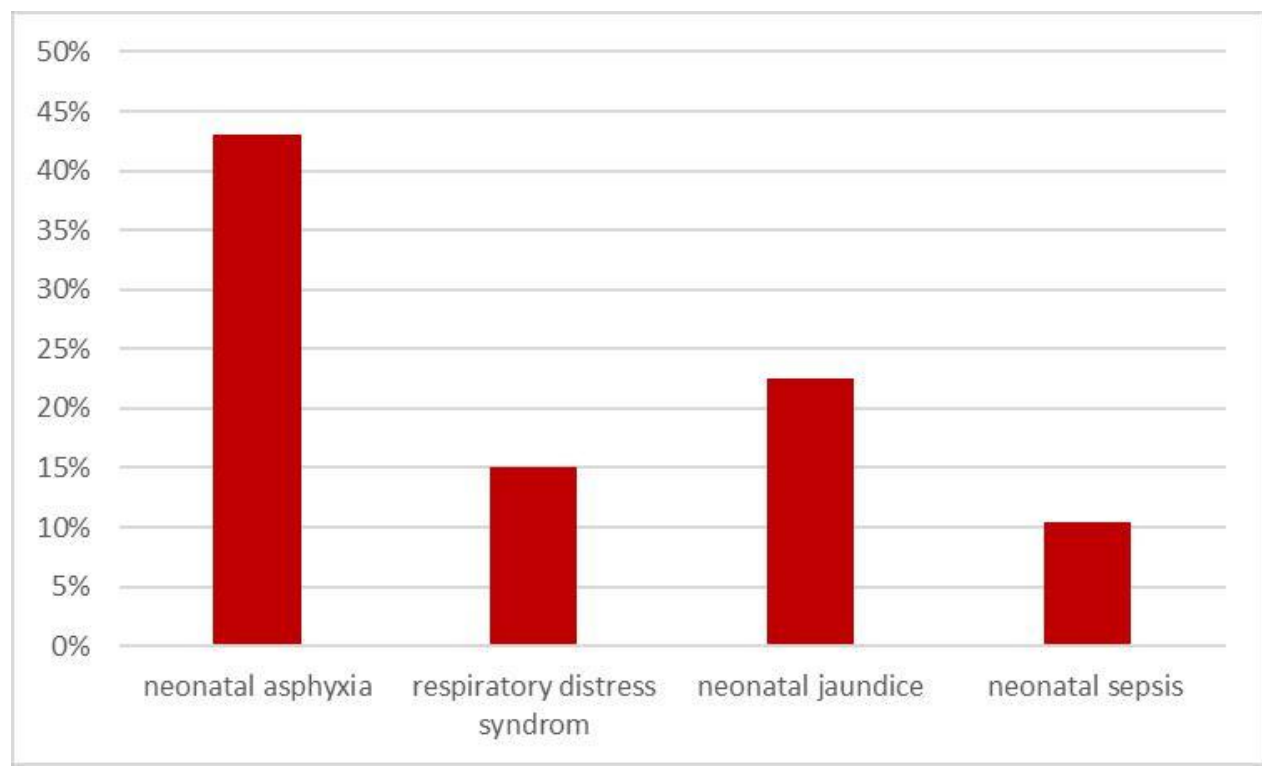

Figure-5: Fetal outcome in 32-34 gestational age

In table-5 shows maternal outcome in 32-34 others diseases. The following table is given below gestational age where most of the women suffered in detail:

from chorioamnionitis which is $67.5 \%$ higher than

Table-5: Maternal adverse outcome in 32-34 gestational age

\begin{tabular}{cc}
\hline Variable & percent \\
\hline Chorioamnionitis & $20 \%$ \\
\hline Endometritis & $12 \%$ \\
\hline Puerperal sepsis & $16 \%$ \\
\hline Abruptio placenta & $10 \%$ \\
\hline Wound infection & $16.4 \%$ \\
\hline
\end{tabular}


In figure- 6 shows distribution of patients according to previous $\mathrm{c} / \mathrm{s}$ prom and previous non $\mathrm{c} / \mathrm{s}$ prom where $57 \%$ had previous c/s prom. The following figure is given below in detail:

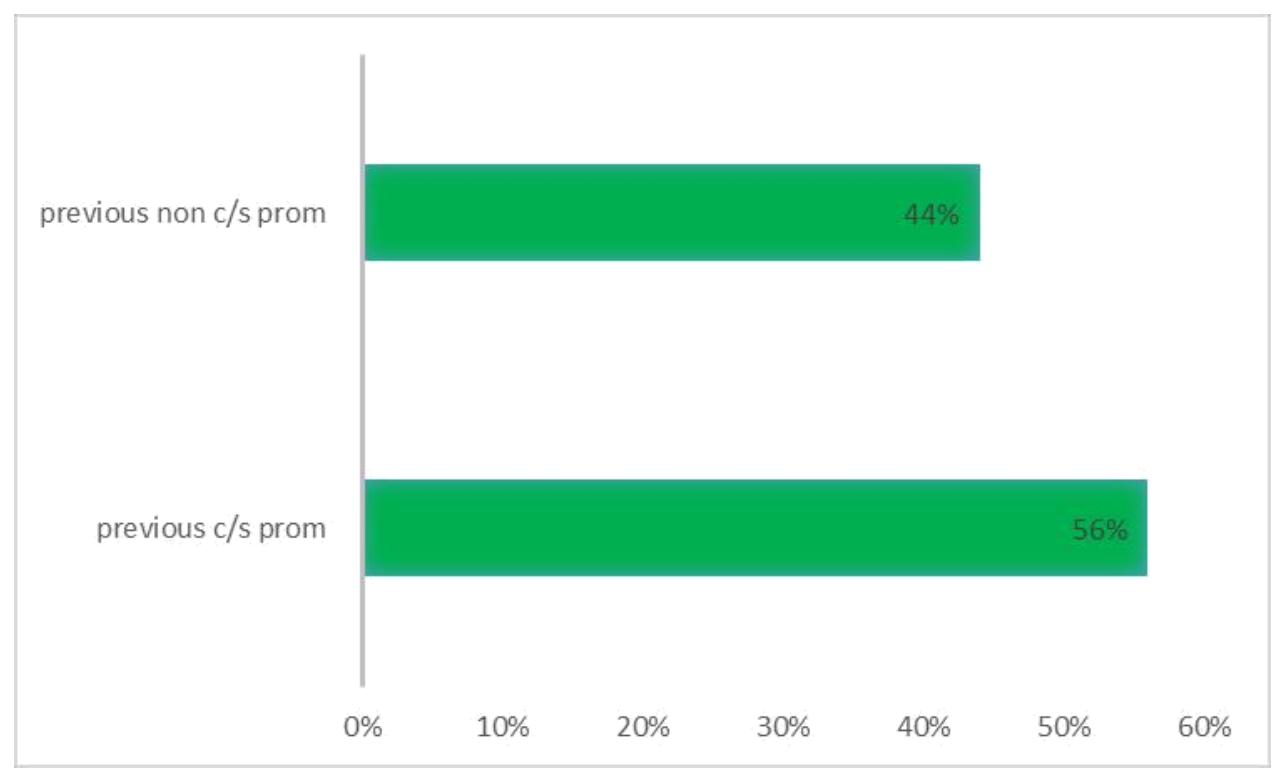

Figure-6: Distribution of patients according to previous c/s prom and previous non c/s prom

In table- 6 shows maternal and fetal condition after 34-36 gestational age where incidence of Peuperal Pyrexia and chorioanmionitis was high in conservative management. The following table is given below in detail:

Table-6: Maternal and fetal condition after 34-36 gestational age

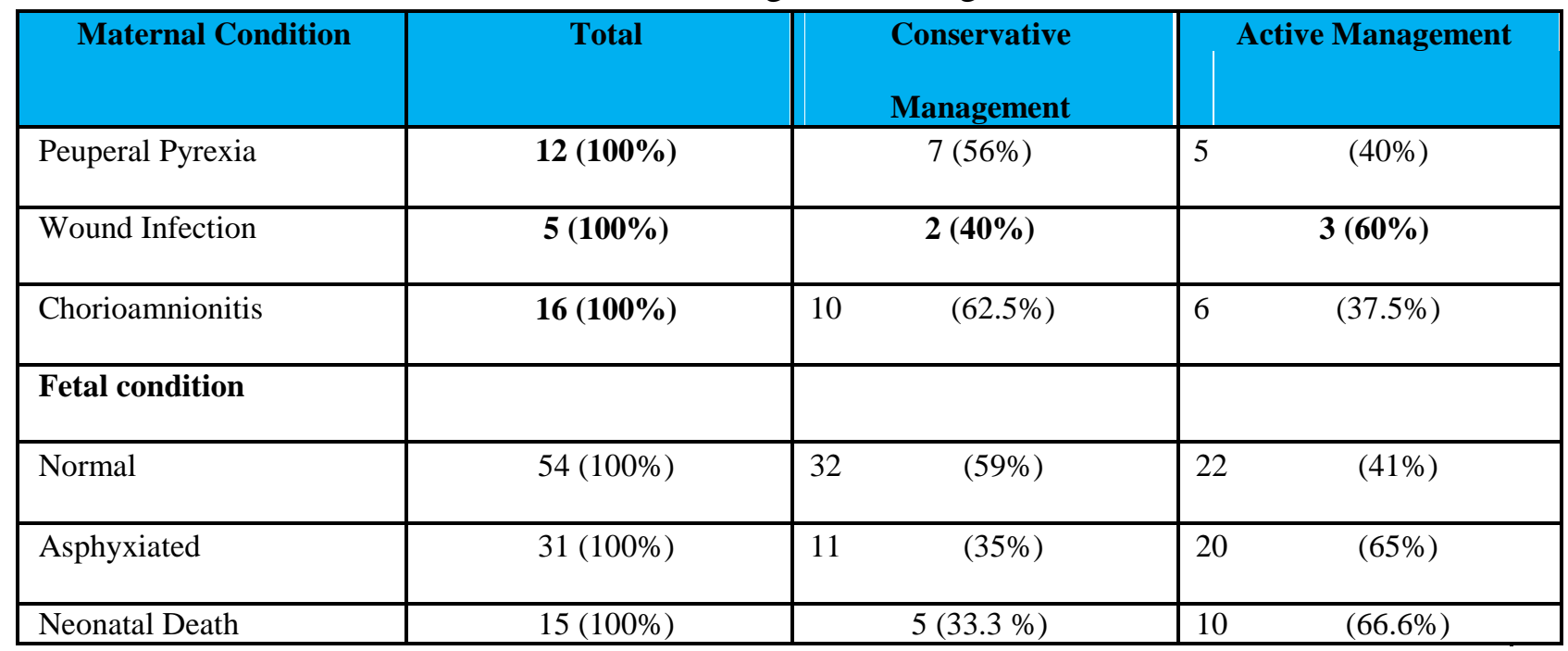

*source by: http://iaimjournal.com/wp-content/uploads/2017/10/iaim_2017_0410_27.pdf

Figure-7 shows analysis of NICU admissions where after NICU admissions 4 neonatal died under conservative management and 7 neonatal died under active management. The following figure is given below in detail: 


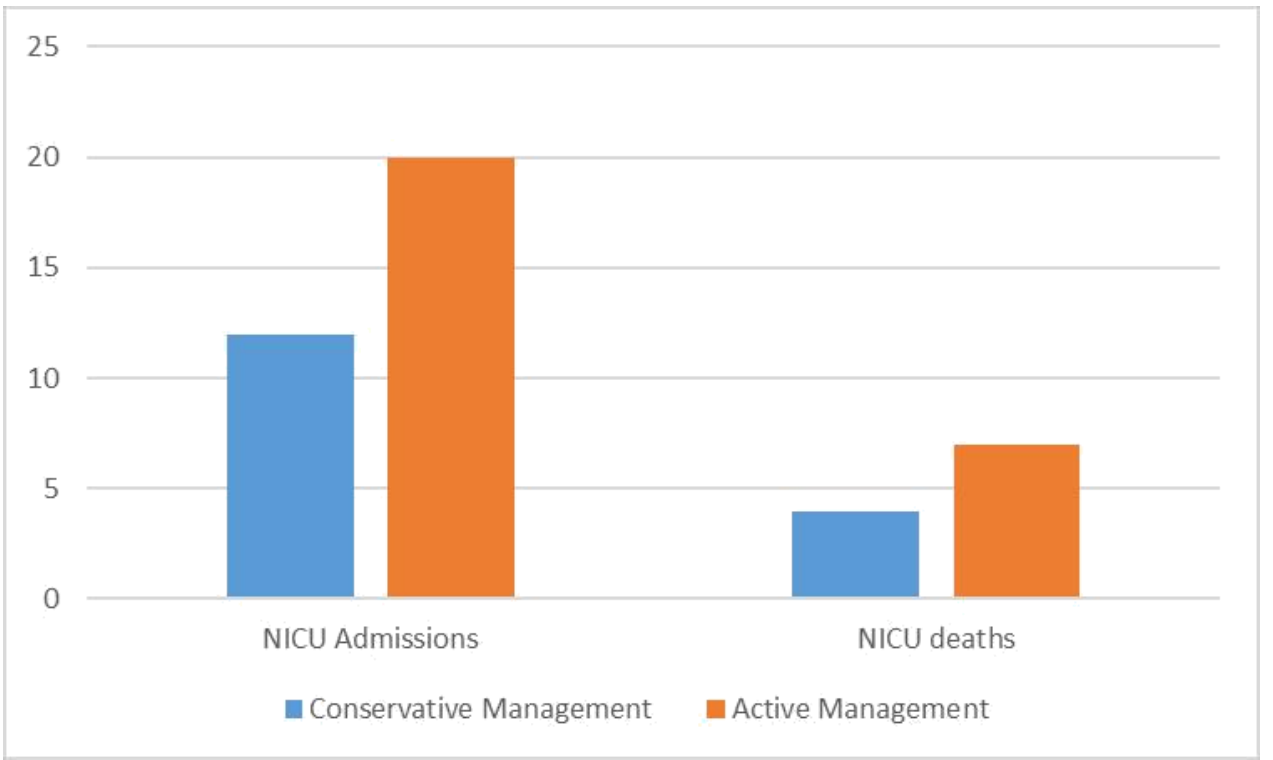

Figure-7: Analysis of NICU Admissions

*source by: http://iaimjournal.com/wp-content/uploads/2017/10/iaim_2017_0410_27.pdf ${ }^{[11]}$

\section{Discussion}

Occurrence of PPROM diverges from country to country and in the same country, from hospital to hospital. It is due to socioeconomic condition of the patient and also of the country. In this study, majority of the women came from lower middle and poor class of the society also PPROM was more common among multiparous women than primi, this findings is opposite to other study. ${ }^{[5]}$ Mean age of the patient was $27.84 \pm 6.278$ years which is similar to other studies ${ }^{[6][7][8]}$. Most of the patients are uneducated and poor. Poverty and illiteracy is interrelated and it affects nutrition, living standard, personal hygiene, immunity and consciousness of the patient. Infection is the most common cause of PPROM and in this study, 16 had UTI, and 7 had lower genital tract infection. Anemia, hypertension and diabetes are associated risk factors of PPROM by affecting nutrition and immunity of the patient produce PROM ${ }^{[9]}$ Coitus increases the incidence of PPROM by causing local trauma and also facilitates microbial entrance into the upper genital tract. This study shows that $60.10 \%$ patients had sexual activity within 2-7days. but lower rate was observed in other study. ${ }^{[5][10]}$ Mean time interval of rupture membrane and delivery was $27.60 \pm 21.128$ hours.
16 women delivered within 24 hours and among them 9 were multi and 7 were primi. Progress of labor is speeded among women with higher gestational age and gravidity. Vaginal delivery is the commonest mode of delivery in PPROM. Regarding neonatal outcome, we assess neonatal weight which was $2.60 \mathrm{~kg}$. $43 \%$ neonates suffered from neonatal asphyxia, respiratory distress syndrome $(15 \%)$, neonatal jaundice $(22.5 \%)$ and neonatal sepsis $(10.5 \%)$ and admitted to special baby care unit. This result is accord with some other studies. ${ }^{[5][6]} \quad 32.5 \%$ suffered from chorioamnionitis, abruptio placenta (15\%), puerperal sepsis $(16 \%)$, endometritis $(20.1 \%)$ and wound infection(16.4\%). Motst of the cases use of antibiotic reduces the risk of Chorioamnionitis.

After 34-36 gestational age incidence of wound infection was high in active management. Maximum duration of hospital stay in active management was 10-12 days. Maximum duration of hospital stay in conservation management was 20- 25 days.

\section{Limitation}

$>$ All pt including term prom cannot included

$>$ Unable to do C-reactive protein and ultrasonography in all cases. 


\section{Conclusion}

From this study we can conclude that majority of the patients were poor, their access to antenatal care was poor and PPROM is malnutrition and poverty related disease. For management PPROM, use of proper antibiotics, steroid administration and conservative $\mathrm{mx}$, NICU facility, reduce hospital stay and ultimately reduce perinatal and maternal complications. Further study is requiring for better outcome.

\section{References}

1. Akter, S., R. Akter, and M. Rashid. "Preterm Prelabour Rupture of the Membrane \& FetoMaternal outcome: an Observational Study." Journal of Bangladesh College of Physicians \& Surgeons 28, no. 1 (2010): 17.

2. Begum, Afrina, Tabassum Ghani, Subinoy Krishna Paul, Taufiqua Hussain, and Noorjahan Begum. "Outcome of Premature Rupture of Membranes-A Study of 120 Cases in Dhaka Medical College Hospital." Journal of Dhaka Medical College 25, no. 2: 82-86.

3. Griff Jones; Pre labour rupture of the membrane; Obstetrics \&Gynaecology-An evidenced based text for MRCOG;Arnold, Member of the hodder headline group.www.arnold publishers.com; 1st edition; Oxford University press; 2004;p297.

4. https://www.google.com/search?client=firefox $a b \&$ tbm=isch \&q=PREMATURE+RUPTURE $+\mathrm{OF}+\mathrm{MEMBRANES} \&$ chips $=\mathrm{q}:$ premature $+\mathrm{ru}$ pture+of+membranes, $g_{-}$ 1:ultrasound:Z_F9pB0k6xA\%3D\&usg=AI4_kTnnPREvjXi7B18aLAjVyn

PFMFYQ\&sa=X\&ved=0ahUKEwjw7rXIirXe AhWMv48KHYSuA5oQ41YIKygD\&biw $=1366 \& \mathrm{bih}=654 \& \mathrm{dpr}=1$ \#imgrc $=\mathrm{PvOHJJCmX}$ fp1iM:

5. Shaheen Rhaman Chowdhury et al; Incidence and outcome of preterm pre mature rupture of membranes and pre term labor at Holy Family
Red Crescent Medical College Hospital, Bangladesh Journal of Obstetrics\& Gynaecology , 2005;20(1),19-24.

6. Tasnim S, A B Bhuiyan: Outcome of premature rupture of membranes; Bangladesh Journal of Obstetrics\& Gynaecology , 1998;13(1),16-20.

7. Begum A, Choudhury: A clinical evaluation of 60 cases; J Inst Postgra Med res 1991; 6:1115.

8. Moretti M, Sibai BM: Maternal and perinatal outcome of expectant management of premature rupture of membranes in the mid trimester; Am J Obstet Gynecol 1988; 159:390-96.

9. Ashley S. Roman,MD,MPH\&Martin L Pernoll,MD. Late pregnancy complication, Current obstetric Gynecologic Diagnosis and treatment. 8th edition. Appleton \& Lange. 1994; 286-87.

10. J Sultana, T A Chowdhury, M H Khan,K Begum: Amniotic fluid index values after preterm premature rupture of the membranes and subsequent prenatal infections ; Bangladesh Journal of Obstetrics\& Gynaecology , 2005;20(2),51-55.

11. Vijetha, B., and N. Suvidha. "Compare the maternal and fetal outcomes in expectant versus active management." 